\title{
Development of a Novel Rolling-Circle Amplification Technique to Detect Banana streak virus that also Discriminates Between Integrated and Episomal Virus Sequences
}

\author{
A. P. James, R. J. Geijskes, J. L. Dale, and R. M. Harding, Centre for Tropical Crops and Biocommodities, Queensland University of \\ Technology, Brisbane, QLD 4001, Australia
}

\begin{abstract}
James, A. P., Geijskes, R. J., Dale, J. L., and Harding, R. M. 2011. Development of a novel rolling-circle amplification technique to detect Banana streak virus that also discriminates between integrated and episomal virus sequences. Plant Dis. 95:57-62.

Banana plants are hosts to a large number of Banana streak virus (BSV) species. However, diagnostic methods for BSV are inadequate because of the considerable genetic and serological diversity among BSV isolates and the presence of integrated BSV sequences in some banana cultivars which leads to false positives. In this study, a sequence-nonspecific, rolling-circle amplification (RCA) technique was developed and shown to overcome these limitations for the detection and subsequent characterization of BSV isolates infecting banana. This technique was shown to discriminate between integrated and episomal BSV DNA, specifically detecting the latter in several banana cultivars known to contain episomal or integrated sequences of Banana streak

Mysore virus (BSMyV), Banana streak OL virus (BSOLV), and Banana streak $G F$ virus (BSGFV). Using RCA, the presence of BSMyV and BSOLV was confirmed in Australia, while BSOLV, BSGFV, Banana streak Uganda I virus (BSUgIV), Banana streak Uganda L virus (BSUgLV), and Banana streak Uganda M virus (BSUgMV) were detected in Uganda. This is the first confirmed report of episomallyderived BSUglV, BSUgLV, and BSUgMV in Uganda. As well as its ability to detect BSV, RCA was shown to detect two other pararetroviruses, Sugarcane bacilliform virus in sugarcane and Cauliflower mosaic virus in turnip.
\end{abstract}

Banana streak virus (BSV), the causal agent of viral leaf streak disease of banana (Musa spp. (L)), occurs in most banana-growing regions worldwide (7). Disease symptoms are highly variable and can include chlorotic and necrotic streaking along the leaf lamina, distortion of leaves and petioles, stem cracking, abnormal bunch development, and death of the growing point (2). In some cases, newly emerging leaves remain symptomless. Yield losses of 6 to $15 \%$ have been associated with streak disease $(3,5)$ and are influenced by the cultivar, virus species, and environmental conditions.

BSV is a member of the genus Badnavirus (family Caulimoviridae) and has a genome comprising noncovalently closed, double-stranded DNA of approximately 7.2 to $7.8 \mathrm{kbp}$. Three BSV species are currently recognized: Banana streak Mysore virus (BSMyV), Banana streak OL virus (BSOLV), and Banana streak GF virus (BSGFV) (20). A fourth species, Banana streak acuminata Vietnam virus (BSAcVNV), has also recently been proposed based on full-length sequence analyses (26). Although partial sequences have been reported for several other putative virus species, including Banana streak Cavendish virus (BSCavV), (9), Banana streak Imové virus (BSImV) and Banana streak Uganda A- to -M viruses (17), the taxonomic status of these viruses remains unresolved.

Integrated Badnavirus sequences, termed endogenous pararetroviruses (EPRVs), are known to occur within the banana genome $(10-12,18,19,24,27)$. Although some EPRV sequences show homology to the genomes of recognized or tentative BSVs, including BSMyV, BSGFV, BSOLV, and BSImV, many others have no known episomal counterpart (11). Two types of integrated BSV sequences are known to occur in banana. The first type contains the majority of banana EPRVs and comprises incomplete virus genomes which are incapable of causing infections. The second type of integrated sequences, known as endogenous activatable BSVs

Corresponding author: A. James, E-mail: ap.james@qut.edu.au

Accepted for publication 10 September 2010.

doi:10.1094/PDIS-07-10-0519

() 2011 The American Phytopathological Society
(eaBSVs), consist of the entire genome of characterized episomal BSVs, which exist as multiple noncontiguous regions of the virus DNA combined with host-genomic sequences. Under certain stress conditions, particularly tissue culture and hybridization, recombination events occur in the integrated sequences, allowing the reconstituted viral genome to be activated and thereby resulting in episomal infections $(1,4,27)$. Although the incomplete integrants have been found in both the $\mathrm{A}$ and $\mathrm{B}$ genomes derived from the wild progenitors of domesticated banana, Musa acuminata and $M$. balbisiana, respectively, the eaBSVs have only been detected in the B genome of various banana accessions $(8,10,12)$.

BSV is highly variable at both the genomic and serological level $(9,12,16-18,26)$, characteristics which present challenges for the development of both polymerase chain reaction (PCR)- and antibody-based diagnostic tests. The presence of integrated Badnavirus sequences further complicates disease diagnosis using PCR-based approaches due to false positives arising from integrated sequences $(19,22,25)$. In an attempt to circumvent the detection of integrated DNA, immunocapture (IC)-PCR is currently used as the "goldstandard" for BSV indexing. However, this method still has serious limitations due to the inability of antiserum to capture all BSV isolates (16); the use of several primer sets which are unlikely to detect the entirety of the BSV sequence diversity; and the presence of contaminating, carryover nucleic acid remaining in capture tubes leading to false positives. As such, an alternative, robust, and sequence-independent diagnostic test is required which not only will enable the specific detection of the circular Badnavirus genome but also will discriminate between episomal and integrated viral DNA.

Rolling-circle amplification (RCA), using bacteriophage Phi29 DNA polymerase, is a sequence-independent protocol which has been used for the amplification and characterization of circular DNA molecules, including plasmids $(6,28)$, and several groups of DNA-viruses infecting humans, animals, and plants (23). To date, the application of RCA technology to plant-infecting viruses has been limited to the small, single-stranded DNA genomes of viruses in the families Geminiviridae and Nanoviridae. In this article, we describe the development and use of RCA as a method for the detection of BSV isolates infecting banana, and demonstrate the ability of this method to differentiate between episomal and integrated 
viral genomic sequences. Further, we report the broader utility of this method for the detection of other pararetroviruses within the family Caulimoviridae.

\section{Materials and Methods}

Plant material. Leaf samples from a known BSMyV-infected banana plant (cv. Cavendish) were generously provided by Dr. Andrew Geering, Department of Employment, Economic Development and Innovation (DEEDI), Indooroopilly Research Centre, Australia. Leaf samples were also obtained from a variety of genotypically diverse Musa cultivars (Table 1), which had been certified as BSV negative using IC-PCR and were maintained in tissue culture at DEEDI, Agri-Science Queensland, Nambour, Australia. Leaf samples were also taken from 12 banana cultivars growing in the field at the DEEDI, Centre for Wet Tropics Agriculture, South Johnstone, Australia, and from 56 banana plants during a field survey in southwest Uganda during April 2008. The latter samples were stored dried over silica gel.

A leaf sample was also obtained from a field-grown sugarcane (Saccharum spp. (L)) plant at the BSES Limited, Northern Experiment Station, Meringa, Australia, which had previously tested positive for the presence of bacilliform particles using immunosorbent electron microscopy (ISEM; 13). Cauliflower mosaic virus (CaMV)-infected forage turnip (Brassica rapa (L) cv. Hunter, field isolate number 4324B) was kindly provided by Dr. Mark Schwinghamer, New South Wales Department of Primary Industries, Tamworth Agricultural Institute, Australia.

Table 1. Selected plant samples used in this study

\begin{tabular}{|c|c|c|c|}
\hline Cultivar & Genotype & $\begin{array}{l}\text { Episomal } \\
\text { virus }\end{array}$ & eaBSV ${ }^{a}$ \\
\hline Calcutta $4^{\mathrm{b}}$ & AA & - & - \\
\hline Pisang Oli ${ }^{\mathrm{b}}$ & AA & - & - \\
\hline Yangambi km5 $5^{\mathrm{b}}$ & AAA & - & - \\
\hline $\mathrm{NC}-301^{\mathrm{b}}$ & AAA & - & - \\
\hline FHIA-17b & AAAA & - & - \\
\hline $\mathrm{Da} \mathrm{Jiao}^{\mathrm{b}}$ & $\mathrm{ABB}$ & - & BSMyV, BSOLV, BSGFV \\
\hline $\mathrm{Ainu}^{\mathrm{b}}$ & $\mathrm{AAB}$ & _- & BSMYV, BSOLV, BSGFV \\
\hline SH-3697 & AAAB & BSOLV & BSMyV, BSOLV, BSGFV \\
\hline SH-3460.10 & AAAB & - & BSMyV, BSOLV, BSGFV \\
\hline FHIA- $03^{\mathrm{b}}$ & AABB & - & BSMYV, BSOLV, BSGFV \\
\hline Balonkawe $^{\mathrm{b}}$ & $\mathrm{ABB}$ & - & BSMyV, BSOLV, BSGFV \\
\hline Goly Goly Pot Pot ${ }^{\mathrm{b}}$ & $\mathrm{ABB}$ & - & BSMYV, BSOLV, BSGFV \\
\hline Lal Velchib & BB & - & BSMyV, BSOLV, BSGFV \\
\hline Cavendish & AAA & BSMyV & - \\
\hline Uganda Green & AAA & BSOLV & - \\
\hline Sukari Ndizi & $\mathrm{AAB}$ & BSGFV & BSMyV, BSOLV, BSGFV \\
\hline
\end{tabular}

a Virus names: endogenous activatable Banana streak virus (eaBSV), Banana streak Mysore virus (BSMyV), Banana streak OL virus (BSOLV), and Banana streak GF virus (BSGFV).

${ }^{\mathrm{b}}$ Denotes tissue-cultured plants.
Nucleic acid extraction. Fresh $(0.4 \mathrm{~g})$ or dried $(0.04 \mathrm{~g})$ leaf tissue was ground in $3 \mathrm{ml}$ of extraction buffer $(100 \mathrm{mM}$ Tris- $\mathrm{HCl}, \mathrm{pH}$ 8.0; 50 mM EDTA; $1.4 \mathrm{M} \mathrm{NaCl} ; 80 \mathrm{mM} \mathrm{Na}_{2} \mathrm{SO}_{3} ; 2 \%$ PVP-10; and $2 \%$ cetyltrimethylammonium bromide) using a mortar and pestle. Samples were incubated at $65^{\circ} \mathrm{C}$ for $15 \mathrm{~min}$ and then centrifuged for $5 \mathrm{~min}$ at $18,000 \times \mathrm{g}$. The supernatant was subsequently mixed with an equal volume of chloroform:isoamylalcohol $(24: 1)$ and the mixture centrifuged at $18,000 \times g$ for $5 \mathrm{~min}$. After a second chloroform extraction, the supernatant was mixed with an equal volume of isopropanol and incubated at room temperature for $5 \mathrm{~min}$. Nucleic acids were pelleted by centrifugation as described above and the pellets were washed with $70 \%$ ethanol, air dried, and resuspended in $50 \mu \mathrm{l}$ of sterile distilled water.

RCA, cloning, and sequencing. DNA was amplified using the Illustra TempliPhi 100 Amplification Kit (GE Healthcare, Buckinghamshire, United Kingdom), essentially according to the manufacturer's instructions but with slight modifications. Nucleic acid extract $(1 \mu \mathrm{l})$ was mixed with $5 \mu \mathrm{l}$ of kit sample buffer and $1 \mu \mathrm{l}$ of a $50-\mu \mathrm{M}$ stock solution (each primer at approximately $4.16 \mathrm{pmol} / \mu \mathrm{l}$ ) of degenerate primers (Table 2). The mixture was denatured at $95^{\circ} \mathrm{C}$ for $3 \mathrm{~min}$ and cooled on ice, and to this was added kit reaction buffer $(5 \mu \mathrm{l})$ premixed with polymerase $(0.2 \mu \mathrm{l})$. The mixtures were incubated at $30^{\circ} \mathrm{C}$ for $18 \mathrm{~h}$ and then the reactions were stopped by incubation at $65^{\circ} \mathrm{C}$ for $10 \mathrm{~min}$. Restriction enzymes (Table 3) were chosen based on analysis of full-length sequences available in GenBank. Restriction analysis was carried out using Vector NTI Advance v.11 (Invitrogen Corp., Carlsbad, CA) for putative single-cutting enzymes (e.g., KpnI) or enzymes generating useful restriction profiles for known BSVs. Additionally, choice of enzyme was based on observations during experimental work for production of polymorphic restriction profiles. Reaction products were digested using two to three units of a restriction endonuclease (Roche, Mannheim, Germany) according to the manufacturer's instructions and then electrophoresed through $1 \%$ agarose gels in Tris-acetate-EDTA buffer at $100 \mathrm{~V}$ for $75 \mathrm{~min}$. Gels were stained using $0.25 \times$ SYBR Safe DNA Gel Stain (Invitrogen Corp.) and DNA fragments visualized on a Safe imager blue-light transilluminator. Bands of interest were excised from gels and purified using the Wizard prep gel purification system (Promega Corp., Madison, WI). The DNA fragments were subsequently ligated into appropriately digested, alkaline phosphatase-treated pUC19 and transformed into competent Escherichia coli. Plasmid DNA was extracted by alkaline lysis and the presence of the cloned fragments was confirmed by restriction digestion.

Sequencing of insert-containing clones was carried out using the BigDye Terminator v3.1 Cycle Sequencing Kit (Applied Biosystems, Foster City, CA) with universal M13 forward and reverse primers, followed by product separation on an Applied Biosystems 3130xl Genetic Analyser (Griffith University DNASequencing Facility, Griffith University, Nathan Campus, QLD, Australia). Where further sequences were required, additional

Table 2. Degenerate primer sequences included in the rolling-circle amplification (RCA) reaction mixes

\begin{tabular}{llc}
\hline Primer name & \multicolumn{1}{c}{ Primer sequence } & Reference \\
\hline 1 A & CTNTAYGARTGGYTNGTNATGCCNTTYGG & 16 \\
$4^{\prime}$ & TCCAYTTRCANAYNSCNCCCCANCC & 16 \\
BadnaFP & ATGCCITTYGGITIAARAAYGCICC & 29 \\
BadnaRP & CCAYTTRCAIACISCICCCCAICC & 29 \\
BSV2292a & ATGARYTAHATWAGRTGYTMSCC & This work \\
BSV2826 & TYYWGAAARCATGGTGGGRGARGA \\
BSV3298 & YTCCCAYCTTTCRAAKACYTT & This work \\
BSV3517 & KRATMTTYTWTYTDGAARATCC \\
BSV3700a & KTGGBAGTTTKGTRAAGARYTC & This work \\
BSV4030 & TGCARRTGYTWYGCYTGYGGAGA & This work \\
BSV6652 & GAAAARRTMTGYGCNTAYGCVAG & This work \\
\hline
\end{tabular}

a Sequence is the reverse compliment of the coding strand of the virus genome.

${ }^{\mathrm{b}}$ Primers developed in this work were designed from an alignment of the complete genome of Banana streak GF virus (NC_007002), Banana streak Mysore virus (NC_006955), Banana streak OL virus (NC_003381), Banana streak acuminata Vietnam virus (AY750155), Banana streak acuminata Yunnan virus (DQ092436) and Banana streak virus isolate GD (DQ451009), and a partial sequence of Banana streak Imové virus (AB252638). Primer name numbers denote the relative position of the $5^{\prime}$ nucleotide of each primer sequence located on the alignment produced using the AlignX function of VectorNTI suite v11. 
sequence-specific primers were synthesized and used for primer walking.

Sequence analysis. The inserts from at least three independent clones were sequenced, with the consensus sequence used for subsequent analyses. Sequences were analyzed using the Vector NTI Advance v.11 suite of programs (Invitrogen Corp.), including ContigExpress to trim vector sequences and Align $X$ to align sequences from clones within a group. The identity of cloned fragments was determined by comparison to published sequence information in National Center for Biotechnology Information database (http://www.ncbi.nlm.nih.gov) using the Basic local alignment search tool programs. According to the ICTV criteria (20) for species demarcation within the genus Badnavirus, sequence differences within the RT/RNaseH-coding region of more than $20 \%$ are considered to be distinct Badnavirus sp. As such, classification of sequences as BSV species was based on sequence comparisons using a 529-bp region of the RT/RNaseH-coding region delimited by the BadnaFP/RP primers reported by Yang et al. (29).

PCR. Three virus-specific primer sets previously shown to detect BSMyV, BSOLV, and BSGFV sequences (9) were used. As an internal control, all extracts were first screened for the banana actin gene using gene-specific primers BanActf $\left(5^{\prime}\right.$ CTGGTGATG GTGTGAGCCAC $\left.3^{\prime}\right)$ and BanActr $\left(5^{\prime}\right.$ CATGAAATAGCT GCGAAACG $3^{\prime}$ ) to generate a 664-bp amplicon. PCR mixes (20 $\mu \mathrm{l}$ ) contained $10 \mu \mathrm{l}$ of $2 \times$ GoTaq Green Master Mix (Promega Corp.), 5 pmol each primer, $1 \mu \mathrm{l}$ of nucleic acid extract, and water to final volume. PCR cycling conditions were an initial denaturation of $94^{\circ} \mathrm{C}$ for $2 \mathrm{~min}$; followed by 35 cycles of $94^{\circ} \mathrm{C}$ for $20 \mathrm{~s}$, $57^{\circ} \mathrm{C}$ for $20 \mathrm{~s}$, and $72^{\circ} \mathrm{C}$ for $30 \mathrm{~s}$; with a final extension at $72^{\circ} \mathrm{C}$ for 2 min. Reactions products were analyzed by agarose gel electrophoresis and amplicons visualized as previously described, except that $1.5 \%$ gels were used.

\section{Results}

RCA can be used to detect and characterize BSV. To assess the ability of RCA to detect a known BSV species, nucleic acid was extracted from a known BSMyV-infected leaf and subjected to RCA using the TempliPhi kit following the manufacturers' instructions. The RCA products were subsequently digested with KpnI because this enzyme's recognition sequence occurs only once in the published BSMyV sequence (Table 3). A very faint, single band of approximately $7.5 \mathrm{kbp}$, presumably representing linear, fulllength genomic DNA, was observed following agarose gel electrophoresis (result not shown). In an attempt to increase amplification, the manufacturer's protocol was modified by the addition of a mixture of degenerate BSV primers (Table 2). When the nucleic acid extract from the known BSMyV-infected leaf was subjected to the modified RCA protocol and the products digested with $K p n I$, a single strong band of approximately $7.5 \mathrm{kbp}$, presumably representing linear, full-length genomic DNA, was observed (Fig. 1A, lanes 1 and 2). Similarly, there were bands of the expected size (Table 3) when RCA-amplified BSMyV samples were digested with BamHI (two sites), EcoRI (two sites), StuI (one site), or XhoI (one site) (results not shown). The approximately 7.5-kbp band derived from the KpnI digest was cloned and approximately
$750 \mathrm{bp}$ at the $5^{\prime}$ and $3^{\prime}$ ends was sequenced. Analyses both confirmed that the sequence was derived from BSMyV, with $99 \%$ nucleotide similarity to the published BSMyV sequence over approximately $1.5 \mathrm{kbp}$ of open reading frame (ORF) 3 , and verified the presence of the predicted KpnI site. Based on these observations, the modified RCA technique was used for all subsequent analyses.

To assess the ability of RCA to detect unknown BSV isolates, leaf samples were taken from 12 banana plants growing in the field in North Queensland. In all, 1 plant (SH-3697) was displaying characteristic leaf streak symptoms while the remaining 11 plants were symptomless. Nucleic acid extracts from each sample were subjected to RCA using the modified method described, and the products were digested with $K p n I$, which was predicted to cut the genomes of BSMyV, BSOLV, BSGFV, and BSAcVNV at a single site (Table 3). A single fragment of approximately $7.5 \mathrm{kbp}$ was observed using the RCA product derived from the leaf of symptomatic plant SH-3697 (Fig. 1A, lanes 3 and 4), whereas no restriction fragments were observed in any of the other digests. To further characterize the BSV isolate presumably infecting plant SH-3697, the RCA product was independently digested with BamHI, EcoRI, $X b a I, S a c I$, and $S t u I$. The restriction profiles were typical of those expected for BSOLV (Table 3) and this presumptive identification was subsequently confirmed by sequence analysis of the approximately 1.2-kbp XbaI-digest fragment, which showed 99\% similarity to a 1,258-bp region of BSOLV ORF3.

To further assess the potential of RCA for the detection and characterization of BSV, an analysis was done on leaf samples collected from 56 field-grown banana plants in southwestern Uganda (sample nos. 1, 2, 5, 7-55, and 57-60), of which 51 showed symptoms of leaf streak disease. When RCA-amplified DNA from these samples was digested using $K p n I$, a fragment of approximately $7.5 \mathrm{kbp}$, presumably representing linear, full-length BSV genomic DNA, was observed in 15 of the samples (sample nos. 5, 8, 11-15, 17, 33, 41, 46, 47, 49, 52, and 60), all of which showed typical symptoms. In addition to the approximately 7.5

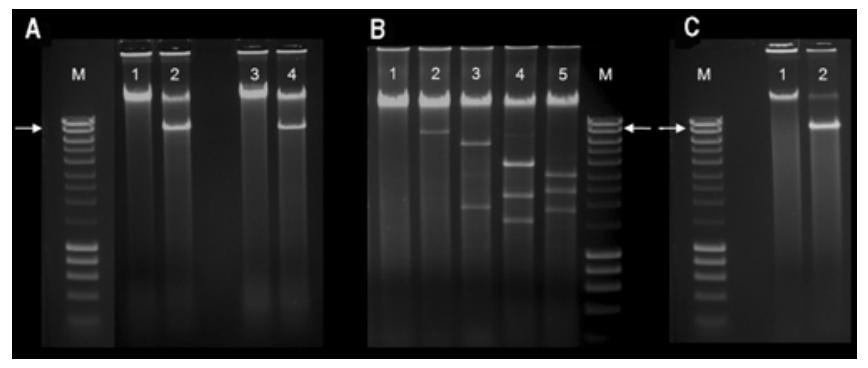

Fig. 1. Agarose gel analysis of rolling-circle amplification (RCA)-amplified DNA. A, Lanes 1 and 3, undigested and lanes 2 and 4, Kpnl-digested RCA products derived from a Banana streak Mysore virus-infected banana and sample SH-3697, respectively; B, lanes 1-5, Stul-digested RCA products derived from Ugandan banana samples $9,10,11,13$, and 14 , respectively; $\mathbf{C}$, lane 1 , undigested and lane 2, Xholdigested RCA products derived from Cauliflower mosaic virus-infected Brassica rapa. Lane M: Hyperladder 1 DNA markers (Bioline (Aust), Alexandria, Australia). Arrow denotes 8-kbp marker fragment.

Table 3. Predicted restriction profiles of genomic DNA from characterized Banana streak virus (BSV) species ${ }^{\mathrm{a}}$

\begin{tabular}{lllcc}
\hline & \multicolumn{4}{c}{ Predicted sizes (bp) of restriction fragments } \\
\cline { 2 - 5 } Restriction enzyme & \multicolumn{1}{c}{ BSMyV } & BSOLV & BSGFV & BSAcVNV \\
\hline Bam $\mathrm{HI}$ & $7,464,186$ & 7,389 & Does not cut & $4,251,3,550$ \\
EcoRI & $7,470,180$ & $5,399,1,006,675,309$ & $3,907,2,723,633$ & $4,213,2,397,780,411$ \\
KpnI & 7,650 & 7,389 & 7,263 & 7,801 \\
$P s t \mathrm{I}$ & $6,881,769$ & $2,635,2,442,2,312$ & $5,657,2,144$ \\
SacI & $3,328,2,984,1,338$ & $2,790,2,769,1,830$ & $5,188,2,613$ \\
StuI & 7,650 & $3,111,2,436,1,842$ & $5,747,45$ & 7,801 \\
XbaI & $3,267,2,458,1,173,629,65,58$ & $4,224,1,907,1,258$ & $6,034,1,229$ & 7,801 \\
XhoI & 7,650 & Does not cut & $5,581,1,667,15$ & Does not cut \\
\hline
\end{tabular}

a Accession numbers for BSV sequences are given in Table 2. Virus names: Banana streak Mysore virus (BSMyV), Banana streak OL virus (BSOLV), Banana streak GF virus (BSGFV), and Banana streak acuminata Vietnam virus (BSAcVNV). 
kbp fragment, digests from one sample (no. 17) contained bands of approximately 3.5 and $4.0 \mathrm{kbp}$, digests from two samples (sample nos. 12 and 49) contained fragments of approximately 5.0 and 2.5 $\mathrm{kbp}$, and the digest from sample no. 46 contained bands of approximately $5.0,3.5$, and $2.5 \mathrm{kbp}$. These results suggested that at least some of the 15 samples were infected with one or more characterized or uncharacterized BSV species. Although restriction profiles distinct from those described above were observed in a further three samples (nos. 37, 44, and 55), two of which displayed typical symptoms, these were not considered to be BSV-specific because the combined size of the digested fragments was less than $7.5 \mathrm{kbp}$. In a further three samples (nos. 39, 40, and 42), all showing typical symptoms, up to eight bands were observed.

In an attempt to detect Ugandan BSV isolates whose genomes lacked a $K p n I$ site, RCA-amplified DNA from all 56 samples was digested with StuI. A band of approximately $7.5 \mathrm{kbp}$, sometimes in combination with additional, smaller-sized bands, was observed in 16 samples (nos. 1, 2, 5, 10, 33, 34, 38, 46, 47, 49, 53, 54, 57, and 58-60) (Fig. 1B, lane 2), 6 of which had previously yielded an approximately $7.5-\mathrm{kbp}$ fragment using KpnI. In all cases, these samples showed symptoms of streak disease. Several distinct restriction profiles were also observed, some of which were indicative of the presence of known BSV species. For example, four samples with symptoms (nos. 14, 17, 47, and 49) produced a restriction profile typical of that expected for BSOLV (Table 3; Fig. 1B, lane 5) while the restriction profile of another two samples with symptoms (nos. 16 and 18) were typical of that expected for BSGFV. Additional distinct restriction profiles, not typical of any characterized BSV species, were also observed which included approximately 5.5- and 1.7-kbp bands (sample nos. 8 and 11) (Fig. 1B, lane 3); approximately 3.7-, 2.2-, and 1.5-kbp bands (sample nos. 12, 13, 19-22, 24-29, 31, 41, and 55) (Fig 1B, lane 4); and approximately 5- and 2.5-kbp bands (sample nos. 32, 44, and 52). Of these samples, only two (nos. 28 and 44) did not display typical symptoms of streak disease. However, sample 28 displayed a mildmosaic symptom, whereas sample 44 was collected due to an abnormal bunching phenotype, another symptom sometimes observed in BSV infections. Interestingly, distinct profiles for more than one virus species were observed in several samples. For example, sample 17 had the BSOLV profile and an additional three fragments of approximately $3.7,2.2$, and $1.5 \mathrm{kbp}$, whereas samples 47 and 49 contained the BSOLV profile as well as distinct, approximately $7.5-\mathrm{kbp}$ fragments, suggesting the presence of a second BSV isolate represented by a full-length digest profile. Although these approximately full-length fragments may represent partially digested BSOLV DNA, distinct, approximately 7.5-kbp bands were not observed in samples 14 and 17, which also had the BSOLV profile. For 6 samples with symptoms (nos. 7, 37, 39, 40, 42 , and 43), the presence of numerous fragments obscured the identification of a distinct profile whereas, for 10 samples, (7 of which had streak symptoms), either no restriction fragments (Fig $1 \mathrm{~B}$, lane 1) were observed or bands were too faint for a distinct profile to be determined.

To identify some of the Ugandan BSV species, the approximately 7.5-kbp, presumably full-length fragments obtained in StuIdigested (sample nos. 1, 2, 10, 47, and 49) or PstI-digested (no. 16) RCA reactions, were cloned. Approximately 750 bp at the $5^{\prime}$ and $3^{\prime}$ ends of the inserts derived from each clone was sequenced. Analyses showed that samples 47 and 49 contained full-length BSGFV, with 90 to $93 \%$ similarity to the published BSGFV sequence. This was an unexpected finding, considering that the published BSGFV sequence contains two StuI restriction sites and, therefore, was expected to produce a restriction profile comprising two fragments of approximately 6 and $1.2 \mathrm{kbp}$, similar to that observed for samples 16 and 18. The presence of BSGFV in sample 16 was verified by sequence analysis of clones derived from the PstI-digested fragment, which showed 98 to $99 \%$ sequence homology to the published BSGFV sequence. The observed variation in the restriction patterns and sequence obtained for BSGFV isolates in samples 47 and 49 , when compared with the published sequence, is indica- tive of the significant sequence variation within BSV isolates comprising a single species. When the approximately 750 -bp sequences at the $5^{\prime}$ and $3^{\prime}$ ends of clones derived from samples 1,2 , and 10 were analyzed, although all three showed 96 to $99 \%$ similarity to each other, they had similarities of only 70 to $80 \%$ to published BSV species. Because sequence similarity within the RT/RNaseHcoding region of Badnavirus spp. is used for species demarcation, primer walking was used to obtain these sequences from clones derived from samples 1 and 2. Subsequent analysis of $529 \mathrm{bp}$ of the RT/RNaseH-coding region derived from samples 1 and 2 revealed that both sequences had 84 to $86 \%$ similarity to Banana streak Uganda L virus (BSUgLV) and $83 \%$ similarity to Banana streak Uganda K virus (BSUgKV).

The approximately 5.5 - and $1.7-\mathrm{kbp}$ fragments resulting from StuI digestion of sample 8 were also cloned and sequenced. Analyses of the $1.7-\mathrm{kbp}$ fragment revealed the presence of motifs typically associated with the RT/RNaseH-coding region of Badnavirus spp., and sequence comparisons revealed 91 to $98 \%$ similarity to Banana streak Uganda I virus (BSUgIV) in the RT/RNaseH-coding region. Similarly, the approximately 3.7-, 2.2-, and 1.5-kbp StuIderived fragments from samples 12 and 13 were cloned and sequenced. The approximately 3.7-kbp fragments from both samples were found to contain motifs typically found in the Badnavirus $\mathrm{RT} / \mathrm{RNaseH}$-coding region, with analyses revealing that both sequences had 90 to $95 \%$ similarity to Banana streak Uganda M virus (BSUgMV). The approximately 5 -kbp fragment from sample 52 was cloned and approximately $750 \mathrm{bp}$ at the $5^{\prime}$ and $3^{\prime}$ ends was sequenced, with analyses showing 92 to $94 \%$ similarity to BSGFV.

To confirm the putative identity of BSOLV in sample 14, the approximately $1.8-\mathrm{kbp}$ fragment was cloned and end sequenced. Analyses confirmed that the fragment matched the predicted 1,842-bp fragment (Table 3) and showed 99\% similarity to the published sequence of BSOLV.

RCA can discriminate between episomal and eaBSVs. To investigate the ability of RCA to selectively amplify episomal and not integrated BSV sequences in banana, leaves from a variety of cultivars were obtained, some of which were known to contain characterized episomal and/or eaBSVs (Table 1). When nucleic acid extracts from each sample were tested by PCR using virusspecific primer sets known to amplify both the episomal and integrated sequences, amplicons of the expected size were observed in all samples known to either be infected with episomal BSV or contain a B genome harboring eaBSVs (Fig. 2A, B, and C). The same extracts were subsequently subjected to RCA followed by digestion with KpnI. Fragments of approximately $7.5 \mathrm{kbp}$ were only observed in the samples known to be infected with episomal $\mathrm{BSV}$, with no digest fragments present in the samples containing only eaBSVs (Fig. 2D).

RCA can be used to detect other pararetroviruses. To determine the utility of RCA to detect other pararetroviruses, nucleic acid was extracted from the leaf of a sugarcane plant shown to be infected with Sugarcane bacilliform virus (SCBV) by ISEM, and from a known CaMV-infected turnip. The RCA product from the SCBV-infected sugarcane sample was digested with $\mathrm{XbaI}$, resulting in several distinct bands, ranging in size from between 4 to $6 \mathrm{kbp}$, as well as numerous smaller bands. This suggested the presence of a heterogeneous population of SCBV isolates. One of the approximately 4-kbp bands was cloned, and sequence analysis of approximately $750 \mathrm{bp}$ at the $5^{\prime}$ and $3^{\prime}$ ends of the cloned inserts showed $94 \%$ nucleotide similarity to Sugarcane bacilliform Morocco virus.

The RCA product from the CaMV-infected turnip sample was separately digested with $\mathrm{XhoI}$ and $\mathrm{StuI}$. XhoI digestion resulted in a single fragment of approximately $7.5 \mathrm{kbp}$ (Fig. 1C), which was presumably linear, full-length, genomic DNA, whereas digestion with $S t u$ I produced two distinct fragments of approximately 3.5 and $4 \mathrm{kbp}$. The approximately 4-kbp fragment was cloned, and approximately $750 \mathrm{bp}$ at the $5^{\prime}$ and $3^{\prime}$ ends was sequenced. Analyses confirmed that the sequence was derived from CaMV (strain B29) with 95 to $96 \%$ nucleotide similarity. 


\section{Discussion}

In this article, we have developed a sequence-nonspecific, RCA methodology for the detection of BSV. Further, using banana samples known to contain characterized episomal or eaBSVs, we have also shown that, unlike PCR, RCA specifically amplifies the circular, episomal genome of BSV and not integrated BSV sequences. The diagnostic capability of RCA for BSV identification was initially validated by the detection of BSMyV in a known virusinfected banana leaf. Subsequently, RCA was used to detect the presence of BSOLV in Australia and Uganda, as well as BSUgIV, BSUgLV, BSUgMV, and BSGFV in Uganda. This is the first confirmed report of episomally derived BSUgIV, BSUgLV, and BSUgMV in Uganda. Although partial sequences of these three viruses have been previously reported (17), their detection using IC-PCR precluded a precise determination of their origin.

An important consideration in the use of RCA for BSV detection is the choice of restriction enzyme used for post-amplification analysis. Clearly, an enzyme which recognizes a single site in the viral genome is preferable because digestion would result in a single, full-length fragment of approximately $7.5 \mathrm{kbp}$. Although such a strategy, using KpnI, was successfully used in this study to detect the previously characterized BSMyV isolate, such an approach is not universally applicable due to the paucity of complete BSV genomic sequences and the considerable sequence variability known to exist within BSV isolates. Pairwise sequence identities among published full-length BSV species is in the order of 57.3 to $60.3 \%$ (26). As such, digestion of RCA products with several different enzymes is necessary to maximize the range of BSV isolates detected. When this approach was used on Ugandan banana leaf samples showing BSV-like symptoms, a variety of different restriction profiles were obtained, only some of which were predicted from the sequences of known BSV isolates. This suggested the presence of multiple characterized or uncharacterized BSV isolates, and this was subsequently confirmed through sequence analysis of a small number of full-length restriction products or fragments derived from distinct restriction profiles. Based on the large number of different restriction profiles observed, it is likely that further cloning and sequencing of additional restriction fragments will result in the identification of further BSV species.

The results from this study have several important implications for BSV diagnostics. BSV is generally regarded as the most important factor limiting the international exchange of banana germ-

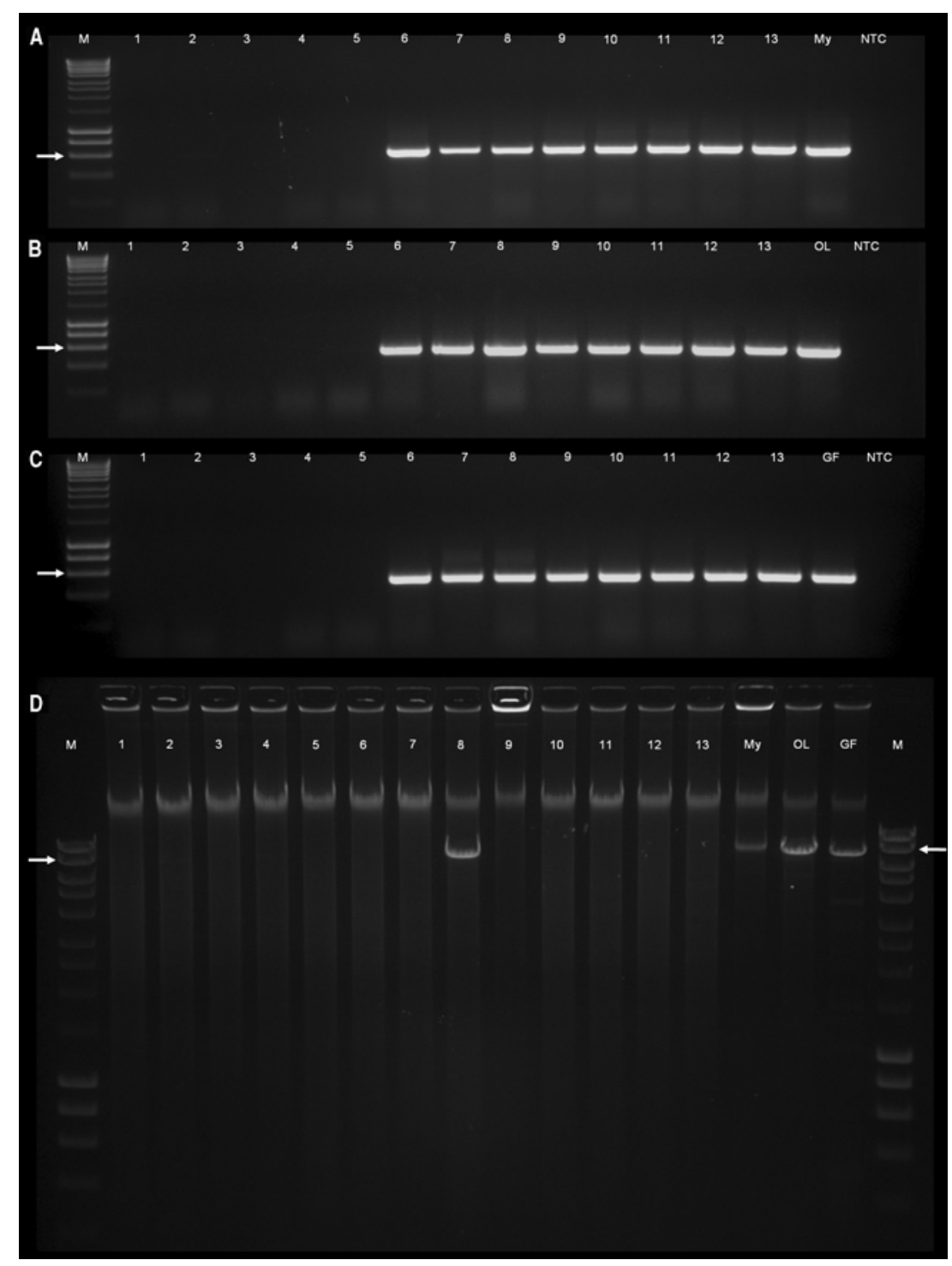

Fig. 2. Comparison of polymerase chain reaction (PCR) and rolling-circle amplification (RCA) for the differential detection of episomal and endogenous activatable Banana streak viruses. A, B, and C, PCR results using Banana streak Mysore virus-, Banana streak OL virus-, and Banana streak GF virus-specific primers, respectively; D, Kpnldigested RCA-amplified DNA. Lane M: Hyperladder 1 DNA markers (Bioline (Aust), Alexandria, Australia); lanes 1-13, extracts derived from cvs. Calcutta 4, Pisang Oli, Yangambi km5, NC-301, FHIA-17, Da Jiao, Ainu, SH-3697, SH-3460.10, FHIA-03, Balonkawe, Goly Goly Pot Pot, and Lal Velchi, respectively; lanes My, OL, and GF = extracts derived from positive control samples Cavendish, Uganda Green, and Sukari Ndizi, respectively; lane NTC, no template control. Arrows denote 600-bp marker fragment $(A, B$, and $C)$ or 8-kbp marker fragment (D). 
plasm for plant breeding and other crop improvement purposes. This is largely due to the lack of reliable and robust diagnostic tests with the capacity to detect the extensive range of genomic and serological variability known to exist within BSV isolates. This problem is exacerbated by the presence of integrated BSV sequences, of which eaBSVs can be activated and cause disease. For the past decade, IC-PCR has been used as the "gold standard" for BSV diagnostics. However, this test has several limitations, including (i) the inability of the antiserum to trap all virus isolates, (ii) the availability of virus-specific primers to amplify only 4 of the at least 19 reported groups or species of $\operatorname{BSV}(9,12,17,18,26)$, and (iii) the occurrence of false positives due to the presence of integrated copies of some BSV species. The sequence-independent nature of RCA, coupled with its ability to selectively amplify circular and not linear (integrated) DNA, overcomes the limitations of IC-PCR. As a result of this study, the number of BSV isolates currently able to be detected has increased from three to at least nine, including BSOLV, BSMyV, BSGFV, BSUg-I, -L, and -MV (this study), as well as BSImV, BSCavV, and BSUgAV (A James, unpublished). This number is likely to be further increased following completion of our sequence analyses of samples collected from extensive surveys in Uganda, Kenya, Tanzania, Rwanda, and Malawi. The identification of a single restriction enzyme capable of diagnosing all BSVs requires further sequence information from episomal Badnavirus spp. infecting banana. Only then may a suitable candidate enzyme be identified for diagnostic purposes.

In addition to its application for BSV detection, we have also demonstrated a broader utility of the RCA methodology for the detection of other plant pararetroviruses. Using RCA, we confirmed the presence of the Badnavirus sp. SCBV in a known SCBV-infected sugarcane sample and also confirmed the presence of the type species of the genus Caulimovirus, CaMV, in a knowninfected sample. Although RCA has been previously used for the detection of DNA genomes of viruses in the families Geminiviridae and Nanoviridae $(14,15,21)$, this is the first report describing the development of RCA for the detection of pararetroviruses belonging to the family Caulimoviridae. The increased amplification observed following the inclusion of degenerate BSV primers is possibly due to target-specific annealing of primers to virus sequences as opposed to random annealing of hexamers included in the kit reagents. This is supported by preliminary observations which have shown an increase in amplification of BSV species from known infected samples using virus-species-specific primers in place of the mixture of degenerate primers.

\section{Acknowledgments}

This research was funded by the Bill and Melinda Gates Foundation Grand Challenges in Global Health Program. We thank C. Changa and J. Kubiriba at the National Agricultural Research Organisation (NARO), Uganda, for assisting with field collections of banana and J. Smith, BSES Limited Meringa, for providing sugarcane samples.

\section{Literature Cited}

1. Côte, F. X., Galzi, S., Folliot, M., Lamagnère, Y., Teycheney, P.-Y., and Iskra-Caruana, M.-L. 2010. Micropropagation by tissue culture triggers differential expression of infectious endogenous Banana streak virus sequences (eBSV) present in the B genome of natural and synthetic interspecific banana plantains. Mol. Plant Pathol. 11:137-144.

2. Dahal, G., Hughes, J., Gauhl, F., Pasberg-Gauhl, C., and Nokoe, K. S. 2000. Symptomatology and development of banana streak, a disease caused by banana streak badnavirus, under natural conditions in Ibadan, Nigeria. Acta Hortic. 540:361-375.

3. Dahal, G., Ortiz, R., Tenkouano, A., Hughes, J. d'A., Thottappilly, G., Vuylsteke, D., and Lockhart, B. E. L. 2000. Relationship between natural occurrence of banana streak badnavirus and symptom expression, relative concentration of viral antigen, and yield characteristics of some micropropagated Musa spp. Plant Pathol. 49:68-79.

4. Dallot, S., Acuña, P., Rivera, C., Ramírez, P., Côte, F., Lockhart, B. E. L., and Caruana, M. L. 2001. Evidence that the proliferation stage of micropropagation procedure is determinant in the expression of Banana streak virus integrated into the genome of the FHIA 21 hybrid (Musa AAAB). Arch. Virol. 146:2179-2190.

5. Daniells, J. W., Geering, A. D. W., Bryde, N. J., and Thomas, J. E. 2001. The effect of Banana streak virus on the growth and yield of dessert ba- nanas in tropical Australia. Ann. Appl. Biol. 139:51-60.

6. Dean, F. B., Nelson, J. R., Giesler, T. L., and Lasken, R. S. 2001. Rapid amplification of plasmid and phage DNA using Phi29 DNA polymerase and multiply-primed rolling circle amplification. Genome Res. 11:1095-1099.

7. Fargette, D., Konaté, G., Fauquet, C., Muller, E., Peterschmitt, M., and Thresh J. M. 2006. Molecular ecology and emergence of tropical plant viruses. Annu. Rev. Phytopathol. 44:235-260.

8. Gayral, P., Noa-Carrazana, J.-C., Lescot, M., Lheureux, F., Lockhart, B. E. L., Matsumoto, T., Piffanelli, P., and Iskra-Caruana, M.-L. 2008. A single Banana streak virus integration event in the banana genome as the origin of infectious endogenous pararetrovirus. J. Virol. 82:6697-6710.

9. Geering, A. W. D., McMichael, L. A., Dietzgen, R. G., and Thomas, J. E. 2000. Genetic diversity among Banana streak virus isolates from Australia. Phytopathology 90:921-927.

10. Geering, A. D. W., Olszewski, N. E., Dahal, G., Thomas, J. E., and Lockhart, B. E. L. 2001. Analysis of the distribution and structure of integrated Banana streak virus DNA in a range of Musa cultivars. Mol. Plant Pathol. 2:207-213.

11. Geering, A. D. W., Olszewski, N. E., Harper, G., Lockhart, B. E. L., Hull, R., and Thomas, J. E. 2005. Banana contains a diverse array of endogenous badnaviruses. J. Gen. Virol. 86:511-520.

12. Geering, A. D. W., Pooggin, M. M., Olszewski, N. E., Lockhart, B. E. L., and Thomas, J. E. 2005. Characterisation of Banana streak Mysore virus and evidence that its DNA is integrated in the B genome of cultivated Musa. Arch. Virol. 150:787-796.

13. Geijskes, R. J., Braithwaite, K. S., Harding, R. M., Dale, J. L., and Smith, G. R. 2002. Sequence analysis of an Australian isolate of sugarcane bacilliform badnavirus. Arch. Virol. 147:2393-2404.

14. Grigoras, I., Timchenko, T., Katul, L., Grande-Pérez, A., Vetten, H.-J., and Gronenborn, B. 2009. Reconstitution of authentic nanovirus from multiple cloned DNAs. J. Virol. 83:10778-10787.

15. Haible, D., Kober, S., and Jeske, H. 2006. Rolling circle amplification revolutionizes diagnosis and genomics of geminiviruses. J. Virol. Methods 135:9-16.

16. Harper, G., Hart, D., Moult, S., and Hull, R. 2002. Detection of Banana streak virus in field samples of bananas from Uganda. Ann. Appl. Biol 141:247-257.

17. Harper, G., Hart, D., Moult, S., Hull, R., Geering, A., and Thomas, J. 2005 The diversity of banana streak virus isolates in Uganda. Arch. Virol. 150:2407-2420.

18. Harper, G., and Hull, R. 1998. Cloning and sequence analysis of banana streak virus DNA. Virus Genes 17:271-278.

19. Harper, G., Osuji, J. O., Heslop-Harrison, J. S., and Hull, R. 1999. Integration of banana streak badnavirus into the Musa genome: molecular and cytogenetic evidence. Virology 255:207-213.

20. Hull, R., Geering, A., Harper, G., Lockhart, B. E., and Schoelz, J. E. 2005. Family Caulimoviridae. Pages 385-396 in: Virus Taxonomy: Eighth Report of the International Committee on Taxonomy of Viruses. C. M. Fauquet, M. A. Mayo, J. Maniloff, U. Desselberger, and L. A. Ball, eds. Elsevier, London.

21. Inoue-Nagata, A. K., Albuquerque, L. C., Rocha, W. B., and Nagata, T. 2004. A simple method for cloning the complete begomovirus genome using the bacteriophage $\varphi 29$ DNA polymerase. J. Virol. Methods 116:209211.

22. Iskra-Caruana, M. L., Gayral, P., Galzi, S., and Laboureau, N. 2009. How to control and prevent the spread of banana streak disease when the origin could be viral sequences integrated in the banana genome? Pages 77-84 in: Proc. IS Banana Crop Prot. Sust. Prod. Impr. Livelihoods. D. Jones and I. Van den Bergh, eds. ISHS.

23. Johne, R., Müller, H., Rector, A., van Ranst, M., and Stevens, H. 2009. Rolling-circle amplification of viral DNA genomes using phi29 polymerase. Trends Microbiol. 17:205-211.

24. LaFleur, D. A., Lockhart, B., and Olszewski, N. E. 1996. Portions of the banana streak badnavirus genome are integrated in the genome of its host Musa sp. (Abstr.) Phytopathology 86:S100.

25. Le Provost, G., Iskra-Caruana, M.-L., Acina, I., and Teycheney, P.-Y. 2006 Improved detection of episomal Banana streak viruses by multiplex immunocapture PCR. J. Virol. Methods 137:7-13.

26. Lheureux, F., Laboureau, N., Muller, E., Lockhart, B. E. L., and IskraCaruana, M. L. 2007. Molecular characterisation of banana streak acuminata Vietnam virus isolated from Musa acuminata siamea (banana cultivar). Arch. Virol. 152:1409-1416.

27. Ndowora, T., Dahal, G., LaFleur, D., Harper, H., Hull, R., Olszewski, N. E. and Lockhart, B. 1999. Evidence that badnavirus infection in Musa can originate from integrated pararetroviral sequences. Virology 255:214-220.

28. Reagin, M. J., Giesler, T. L., Merla, A. L., Resetar-Gerke, J. M., Kapolka, K. M., and Mamone, J. A. 2003. TempliPhi: A sequencing template preparation procedure that eliminates overnight cultures and DNA purification. J. Biomol. Tech. 14:143-148.

29. Yang, I. C., Hafner, G. J., Revill, P. A., Dale, J. L., and Harding, R. M 2003. Sequence diversity of South Pacific isolates of taro bacilliform virus and the development of a PCR-based diagnostic test. Arch. Virol. 148:19571968 . 